\title{
Ex vivo drug sensitivity profiles of Plasmodium falciparum field isolates from Cambodia and Thailand, 2005 to 2010, determined by a histidine-rich protein-2 assay
}

\author{
Stuart D Tyner ${ }^{1 \dagger}$, Chanthap Lon ${ }^{1 * \dagger}$, Youry Se ${ }^{1}$, Delia Bethell ${ }^{1}$, Doung Socheat ${ }^{2}$, Harald Noedl $^{3}$, Darapiseth Sea ${ }^{2}$, \\ Wichai Satimai ${ }^{4}$, Kurt Schaecher ${ }^{1}$, Wiriya Rutvisuttinunt ${ }^{1}$, Mark M Fukuda', Suwanna Chaorattanakawee', \\ Kritsanai Yingyuen', Siratchana Sundrakes ${ }^{1}$, Panjaporn Chaichana', Piyaporn Saingam", Nillawan Buathong ${ }^{1}$, \\ Sabaithip Sriwichai', Soklyda Chann ${ }^{1}$, Ans Timmermans ${ }^{1}$, David L Saunders ${ }^{1}$ and Douglas S Walsh'1
}

\begin{abstract}
Background: In vitro drug susceptibility assay of Plasmodium falciparum field isolates processed "immediate ex vivo" (IEV), without culture adaption, and tested using histidine-rich protein-2 (HRP-2) detection as an assay, is an expedient way to track drug resistance.

Methods: From 2005 to 2010, a HRP-2 in vitro assay assessed 451 P. falciparum field isolates obtained from subjects with malaria in western and northern Cambodia, and eastern Thailand, processed IEV, for 50\% inhibitory concentrations $\left(\mathrm{IC}_{50}\right)$ against seven anti-malarial drugs, including artesunate $(\mathrm{AS})$, dihydroartemisinin $(\mathrm{DHA})$, and piperaquine.

Results: In western Cambodia, from 2006 to 2010, geometric mean (GM) IC 50 values for chloroquine, mefloquine, quinine, AS, DHA, and lumefantrine increased. In northern Cambodia, from 2009-2010, GM IC 50 values for most drugs approximated the highest western Cambodia GM IC 50 values in 2009 or 2010.

Conclusions: Western Cambodia is associated with sustained reductions in anti-malarial drug susceptibility, including the artemisinins, with possible emergence, or spread, to northern Cambodia. This potential public health crisis supports continued in vitro drug $I C_{50}$ monitoring of $P$. falciparum isolates at key locations in the region.
\end{abstract}

Keywords: Cambodia, malaria, Plasmodium falciparum, HRP-2, Anti-malarial drugs, Drug resistance

\section{Background}

Since the 1980s, measuring in vitro drug $50 \%$ inhibitory concentrations $\left(\mathrm{IC}_{50}\right)$ against $P$. falciparum field isolates has been useful in tracking clinical drug susceptibility patterns [1-3]. In Southeast Asia, especially along the Thailand-Cambodia border, changes in drug susceptibility often emerge first, with worldwide implications,

\footnotetext{
* Correspondence: ChanthapL@afrims.org

${ }^{\dagger}$ Equal contributors

'Department of Immunology and Medicine, US Army Medical Corps, Armed Forces Research Institute of Medical Sciences (USAMC-AFRIMS), Bangkok,

Thailand

Full list of author information is available at the end of the article
}

underscoring the region's importance as a sentinel site for anti-malarial drug resistance [3].

In 2003, artesunate (AS) + mefloquine (MQ) was implemented as the first-line artemisinin-combination therapy (ACT) for falciparum malaria in Cambodia. By 2005, subjects with falciparum malaria along Thai-Cambodia border treated with oral artesunate were showing longer parasite clearance times, suggesting the emergence of reduced susceptibility to artemisinins, as well as to the partner drug [4].

The non-radioisotope histidine-rich protein-2 (HRP-2) ELISA, a relatively sensitive assay, which reliably depicts drug $\mathrm{IC}_{50}$ values for $P$. falciparum isolates, reduces obstacles for conducting assays in remote settings [5,6].

\section{() Biomed Central}

(c) 2012 Tyner et al. This is an Open Access article distributed under the terms of the Creative Commons Attribution License (http://creativecommons.org/licenses/by/2.0), which permits unrestricted use, distribution, and reproduction in any medium, provided the original work is properly cited. 
HRP-2 assays are expedient, safer and less costly than radioisotope assays. HRP-2 assay, when field deployed proximal to $P$. falciparum collection sites, allows for "immediate ex vivo" (IEV) field isolate processing [7]. IEV, by avoiding cryopreservation and culture-adaptation before $\mathrm{IC}_{50}$ determination, may reduce clonal selection, better preserving parasite subpopulations with variable drug susceptibility profiles, the latter likely present in a smaller proportion than wild-type drug susceptible parasites.

Here, to characterize recent geographical and temporal trends in western and northern Cambodia, and eastern Thailand, including years when reduced artemisinin susceptibility was first described, an HRP-2 assay, with IEV field isolate processing was used to determine $\mathrm{IC}_{50}$ values of $P$. falciparum field isolates obtained from 2005 to 2010 .

\section{Methods}

\section{Protocol, sites and subjects}

All studies were approved by 1 or more ethical review boards which included Cambodian National Ethics Committee for Health Research (NECHR), Ethical Review Committee for Research in Human Subjects, Thailand Ministry of Public Health (MoPH), Walter Reed Army Institute of Research (WRAIR) Institutional Review Board and World Health Organization (WHO) Ethical Review Committee (protocol numbers: WRAIR 973, WRAIR 1327, WRAIR 1296, WRAIR 1396, WRAIR 1576, and WRAIR 1737). All protocols complied with International Conference on Harmonization Good Clinical Practice (ICH-GCP) guidelines. Enrollment centers were located in western and northern Cambodia (Pailin, Battambang, Oddar Meanchey and Preah Vihear Provinces (Figure 1), and Trat, eastern Thailand. All sites were considered low transmission, malaria endemic regions at the time of sample collection $[8,9]$.

Among six studies involved in subject recruitment, summarized in Table 1, subjects of five to 70 years of age with smear-confirmed, uncomplicated $P$. falciparum malaria were eligible to participate. Written informed consent was obtained from adult subjects, or from legal guardians with assent from minors. Subjects who gave a history of anti-malarial drug use within the previous 730 days, were pregnant or nursing, or who had signs suggestive of severe malaria, were excluded from participation (Table 1). Treatment following malaria diagnosis was according to national standards of care at the respective times, or involved randomized allocation to an artemisinin containing regimen as part of an interventional clinical trial.

\section{Malaria microscopy}

Microscopic examination of Giemsa-stained peripheral blood smears was performed by two microscopists for each subject (200 high-powered fields [HPF] per reader) to determine parasitaemia, and presence/absence of a second malaria species. Microscopists conducted all reads in the thick smear unless there were $>500$ parasites/200 WBCs, in which case they switched to the thin smear. Discrepancies between microscopists were resolved in real-time by a third reader (reviewing an additional $200 \mathrm{HPFs}$ ), who determined the final result. Parasite density was calculated as the number of parasites/200 WBC's in the thick smear or the number of parasites/5000 RBC's in the thin smear. A geometric mean (GM) of the two microscopist's results was used as the final parasitaemia for each subject. Time zero peripheral blood specimens from WRAIR 1396, 1576, and 1737 were also confirmed by species-specific real-time PCR (RT-PCR) targeting the 18 s rRNA gene. Specimens with a microscopically or RT-PCR confirmed malaria coinfection at time zero, Plasmodium vivax or other malaria species, were excluded from analysis. Subject parasite density ranges at study enrolment are shown in Table 1.

\section{Sample collection and preparation}

Enrolled subjects provided up to $8 \mathrm{ml}$ of venous blood in sodium heparin tubes for the HRP-2 ex vivo $\mathrm{IC}_{50}$ assay. In all cases, P. falciparum isolates from submitting study locations were plated directly onto malaria drug coated plates without prior culture adaptation [5]. All applications of falciparum isolates to drug coated plate occurred at field sites or in central laboratories located at Battambang Referral Hospital (BRH) or at Anlong Veng Health Center (AVHC). Samples analyzed at BRH or AVHC were refrigerated during transportation $\left(2-8^{\circ}\right.$ C) and plated $<6$ hours after being drawn from the subject.

\section{Drugs and plate coating}

Seven anti-malarial drugs for $\mathrm{IC}_{50}$ testing were used: chloroquine diphosphate (CQ), mefloquine hydrochloride (MQ), quinine sulfate hydrate (QN) artesunate (AS), dihydroartemisinin (DHA), lumefantrine (LUM) and piperaquine (PPQ). CQ, MQ, QN and PPQ were provided as salts, AS, DHA, and LUM as bases. All drug stocks were prepared using a weight/volume convention with salt or base formulation weights used to calculate $\mathrm{nM} \mathrm{IC}_{50}$ values. Test drugs were provided by Walter Reed Army Institute of Research (Silver Spring, Maryland, USA).

To prepare test drugs, stock drug solutions at $1 \mathrm{mg} /$ $\mathrm{mL}$ were prepared in $70 \%$ ethanol for DHA, AS, MQ, QN, and CQ or a solution of $100 \%$ ethanol : linoleic acid : Tween 80 (1:1:1) for LUM and 0.5\% lactic acid in distilled water for PPQ. Further drug dilutions were performed in distilled water for DHA, AS, MQ, QN, CQ, 


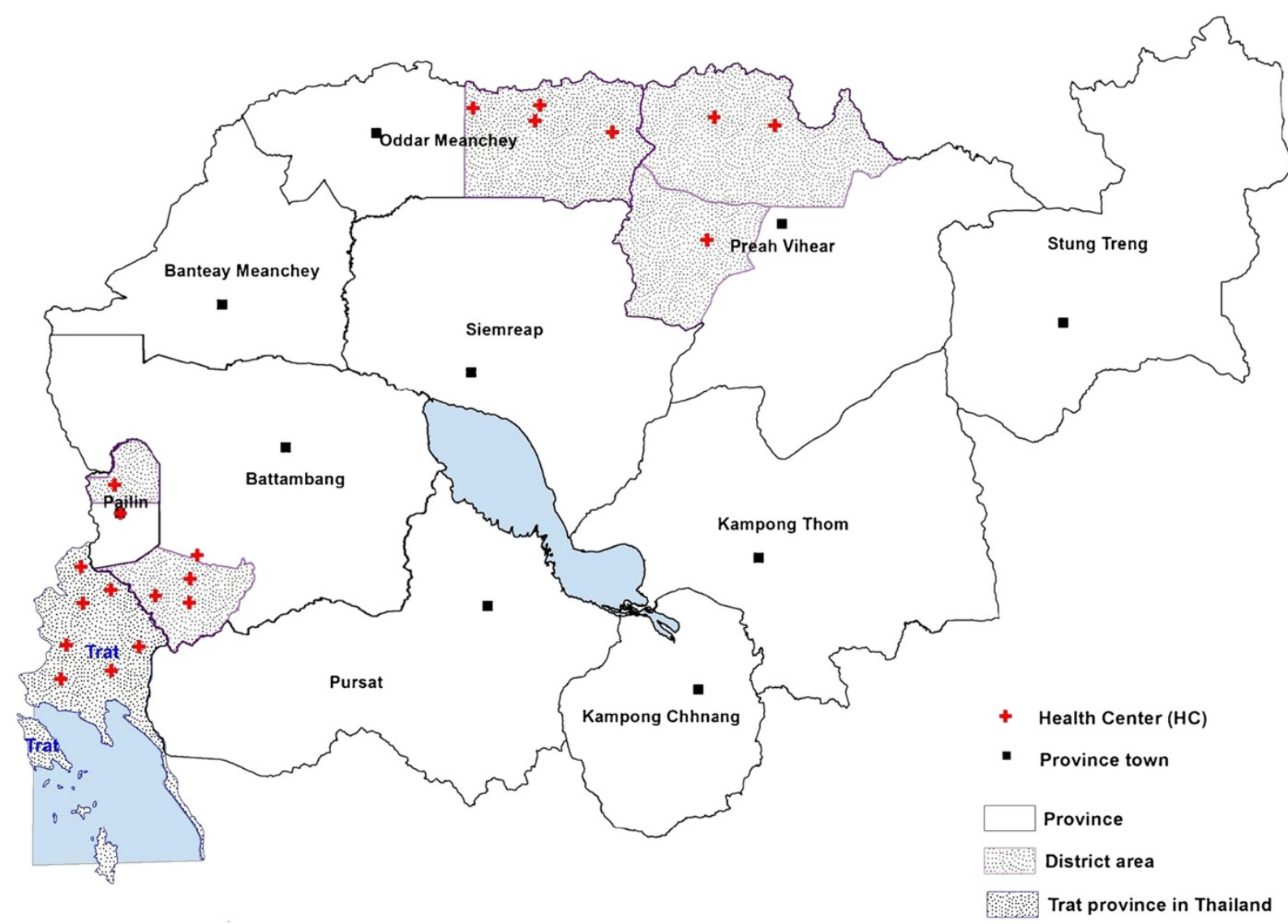

Figure 1 Map depicting provinces in Cambodia and Thailand (shaded) where P. falciparum isolates were obtained.

and PPQ or $70 \%$ ethanol for LUM to the desired starting concentration, followed by serial 3 -fold dilutions to generate 7 concentrations for $\mathrm{IC}_{50}$ testing. The last row of the drug plate contained no drugs. Dried drug coated plates were prepared as described $[5,6,10]$.

The concentration ranges $(\mathrm{ng} / \mathrm{ml})$, from highest to lowest, and molecular weights $(\mathrm{g} / \mathrm{mole})$ used to convert to $\mathrm{nM}$ were, respectively: CQ (2000 to $2.74 ; 515.92)$, MQ (200 to $0.274 ; 414.78), \mathrm{QN}(1250$ to $1.71 ; 782.97)$, AS (20 to $0.027 ; 384.42$ ), DHA (20 to $0.027 ; 284.35$ ), LUM (50 to $0.07 ; 528.95)$ and PPQ (625 to $0.86 ; 999.56)$. The drug solutions were prepared and used within one week. Drug solutions were stored at $2-8^{\circ} \mathrm{C}$ and used within 1 week of preparation.

\section{Plasmodium falciparum W2 reference clone and quality control}

W2, a well characterized $P$. falciparum laboratory reference clone, recovered from cryopreserved sample and maintained in continuous culture for $\leq 5$ months, served as quality control for drug coating plate lots and to assess assay performance within a previously validated acceptable range. W2 also served as a comparator for $P$. falciparum field isolate $\mathrm{IC}_{50}$ values. W2 $\mathrm{IC}_{50}$ assays against each drug were conducted annually from 2008 to 2010. W2, in vitro, is considered CQ "resistant" (CQ-R), and MQ "susceptible" (MQ-S). The W2 GM IC 50 values of CQ, MQ and QN, especially when assessed simultaneously with $P$. falciparum field isolates, provide context for non-radioisotopic IEV assays [11]. W2 has no defined $\mathrm{IC}_{50}$ value discriminative for AS or DHA "resistance".

Earlier reports describe drug $\mathrm{IC}_{50}$ "cut-off" values for "culture-adapted" P. falciparum field isolates, once generally considered discriminative for in vivo resistance; these include CQ (>45.5 ng/ml; $85 \mathrm{nM})$, MQ (> $10 \mathrm{ng} /$ $\mathrm{ml} ; 24 \mathrm{nM}$ ), and QN (> $275 \mathrm{ng} / \mathrm{ml} ; 351 \mathrm{nM})[12,13]$. These historical cut-off values may provide rough context, primarily for assay reliability, and perhaps for $P$. falciparum field isolate $\mathrm{IC}_{50}$ trends, including nonradioisotopic IEV assays [11].

For quality control (QC), conducted from 2008 to 2010, a subset of all drug-plate coating lots was tested using the HRP-2 assay with $\mathrm{W} 2$ and an $\mathrm{IC}_{50}$ value was derived for each anti-malarial compound before the lot was sent to the field. Lots that performed within previously validated criteria were cleared to be sent to the field. Out of range lots were destroyed. Drug plating consistency and stability between different lots were 
Table 1 Studies providing $P$. falciparum isolates for HRP-2 $\mathrm{IC}_{50}$ drug assays

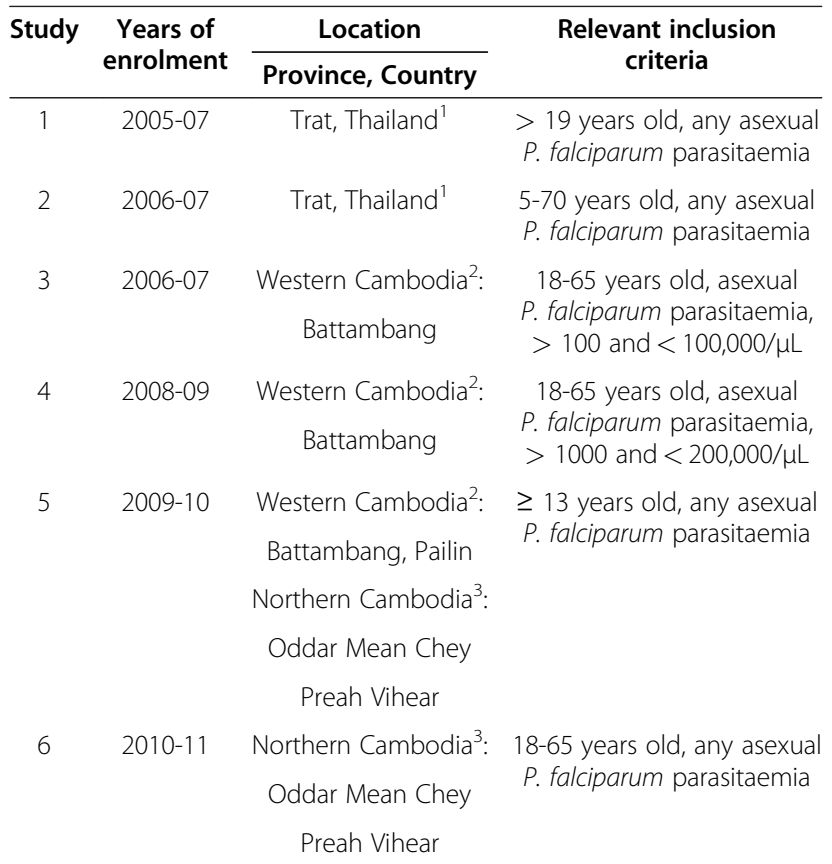

${ }^{1}$ Thailand Ministry of Public Health Clinics in Borai, Khaosaming and Muang districts.

${ }^{2}$ Western Cambodia: Pailin (Pailin Hospital) and Battambang Provinces (Tasanh, Samlot, Chanlong Kuoy and Kampong Lpov health centers);

${ }^{3}$ Northern Cambodia: Oddar Mean Chey (Anlong Veng, Trapang Tav, Trapang

Prey, Trapang Prasat and Sraem health centers), and Preah Vihear Provinces.

consistent with previous reports [14]. A subset of each plate-coating lot taken to the field was stored refrigerated $\left(2-8^{\circ} \mathrm{C}\right)$ for up to 8 weeks, then transported back to the AFRIMS laboratory in Bangkok where QC was performed again with W2, to determine if transport and storage conditions in the field affected $\mathrm{IC}_{50}$ analysis.

\section{HRP-2 IC I0 $_{50}$ drug susceptibility assay}

An established HRP-2 $\mathrm{IC}_{50}$ drug susceptibility assay was used to assess each $P$. falciparum field isolate, processed immediate ex vivo $[5,6]$. Falciparum isolates were processed within six hours after phlebotomy, including parasitaemia adjustment, as previously described, then placed onto drug coated plates (0 hours) [5,15]. Falciparum isolates within the range of plate parasitaemia $(0.2 \%-0.5 \%)$ were immediately transferred to the drug coated plates as the $0 \mathrm{hr}$ screening sample; samples with a parasitaemia $>0.5 \%$ were diluted to within the plate parasitaemia range by adding 50\% haematocrit human $\mathrm{O}+$ red blood cells in 10\% serum RPMI 1640 culture media; and samples with a parasitaemia below $0.2 \%$ were plated without adjustment [15].

Samples $(\sim 200 \mu \mathrm{l})$ from untreated wells were collected every 24 hours for 72 hours, with parasite growth rate interpreted as the difference in HRP-2 production between 0 and 72 hours. Due to the high sensitivity of the HRP-2 assay, dilution of the samples was sometimes required before performing the ELISA to bring the concentration within assay OD range.

\section{Statistical analysis of $\mathrm{IC}_{50}$ values}

HRP-2 optical densities (OD) were plotted against drug concentrations and $\mathrm{IC}_{50}$ values estimated by nonlinear regression analysis using ICEstimator [16]. In P. falciparum field isolates which showed measurable growth, ICEstimator rules were used to determine the concentration-response relationship and $\mathrm{IC}_{50}$, i.e., ratio of growth without drug to that with maximum drug, For each drug, $\mathrm{IC}_{50}$ values were expressed as geometric means (GM). Statistical significance within and between groups was determined by nonparametric Kruskal-Wallis or Mann-Whitney tests, as indicated (Graph-Pad Prism 4, GraphPad Software, Inc., La Jolla, California, USA).

\section{Results}

HRP-2 $\mathrm{IC}_{50}$ drug assays

Among 590 P. falciparum isolates collected, $\mathrm{IC}_{50}$ values on 451 (76\%) were obtained.

The success rate for all assays was about $75 \%$, including $78 \%$ with a parasitaemia $>0.5 \%$ and $61 \%$ with a parasitaemia $\leq 0.5$.

Figure 2 (a-g) shows individual and geometric mean (GM) $\mathrm{IC}_{50}$ values for IEV P. falciparum field isolates, by location and year, and W2 P. falciparum reference clone (CQ-R, MQ-S, QN-S, artemisinin-S) $\mathrm{IC}_{50}$ values against each drug. In western Cambodia, assessed annually from 2006 to 2010, geometric mean $\mathrm{GM} \mathrm{IC} 50$ values for CQ, MQ QN, AS, DHA, and LUM increased $(\mathrm{p}<0.05)$. In northern Cambodia, assessed in 2009 and 2010, GM $\mathrm{IC}_{50}$ values for most drugs approximated the highest western Cambodia GM IC 50 values in 2009 or 2010. In Thailand, assessed in 2005 and 2007, GM IC 50 values increased for QN and DHA ( $\mathrm{p}<0.05)$.

\section{Discussion}

Among $P$. falciparum field isolates obtained in western Cambodia from 2005 to 2010, steady increases were observed for $\mathrm{GM} \mathrm{IC}_{50}$ values measured by a HRP-2 in vitro assay against a range of anti-malarial drugs, including AS and DHA. Moreover, in northern Cambodia, assessed in 2009 and 2010, most GM IC 50 values approximated those in western Cambodia, during the same period. This supports the notion that western Cambodia is associated with sustained and likely progressive reductions in anti-malarial drug susceptibility, with possible spread to northern Cambodia.

As the same HRP-2 IEV assay was used for all P. falciparum field isolates, increasing $\mathrm{GM} \mathrm{IC}_{50}$ values for $\mathrm{AS}$ and DHA may reflect possible emerging artemisinin 
a

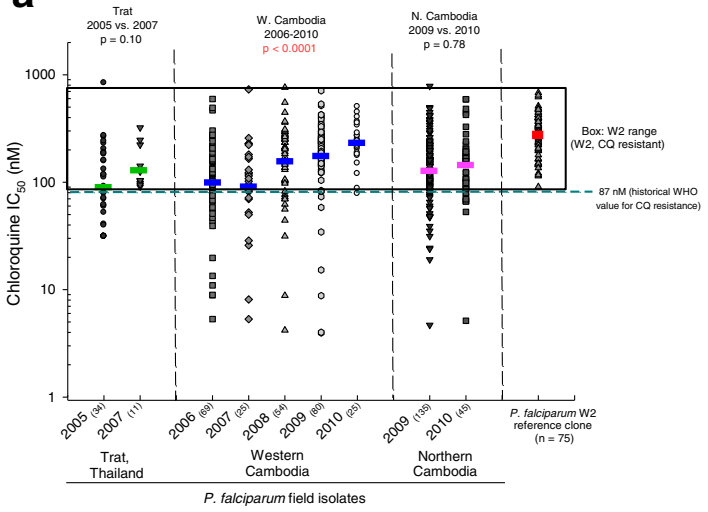

C

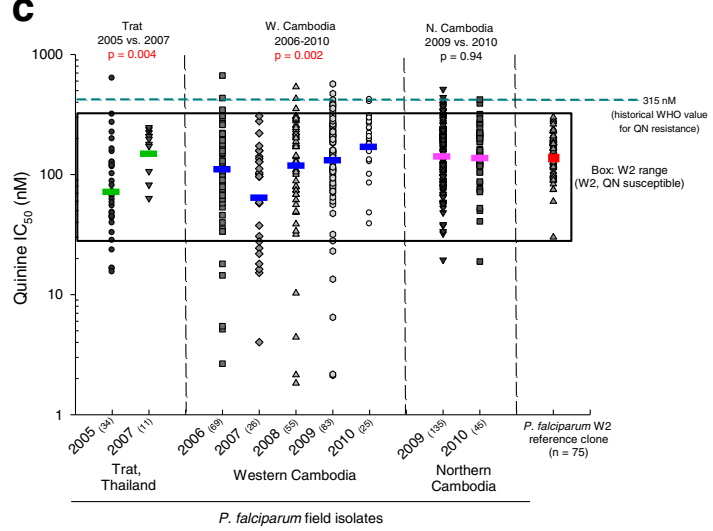

e

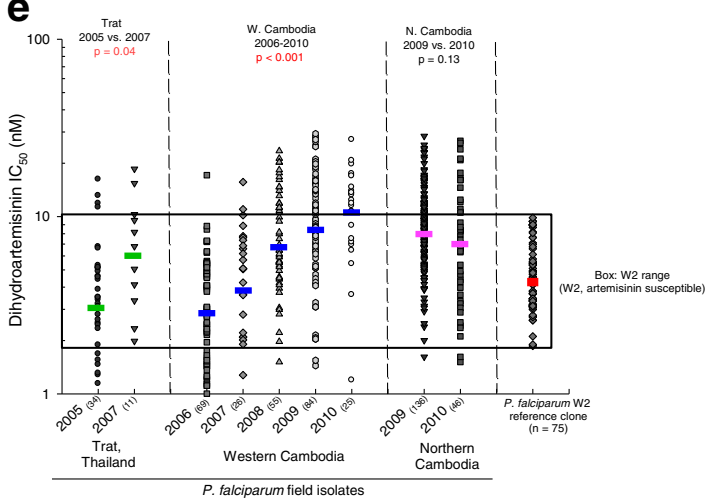

g

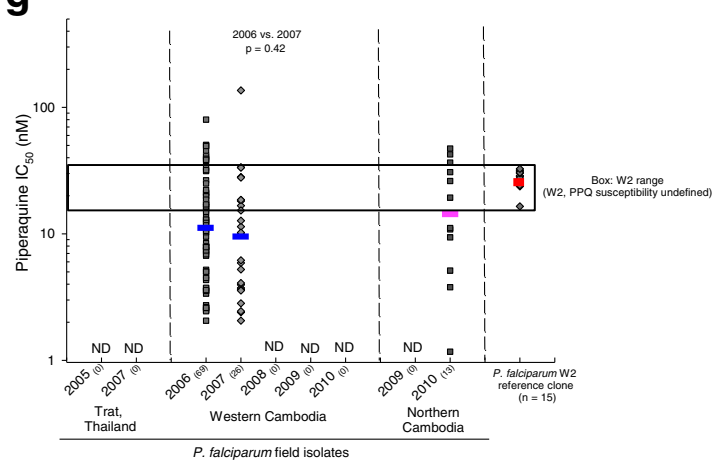

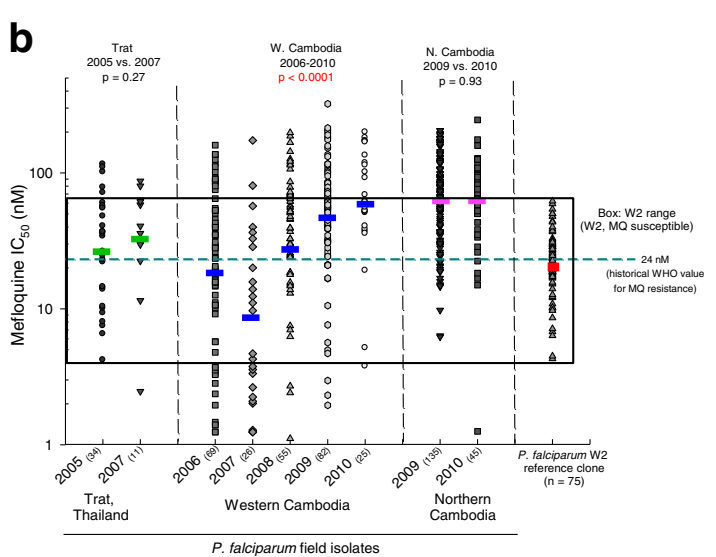

d
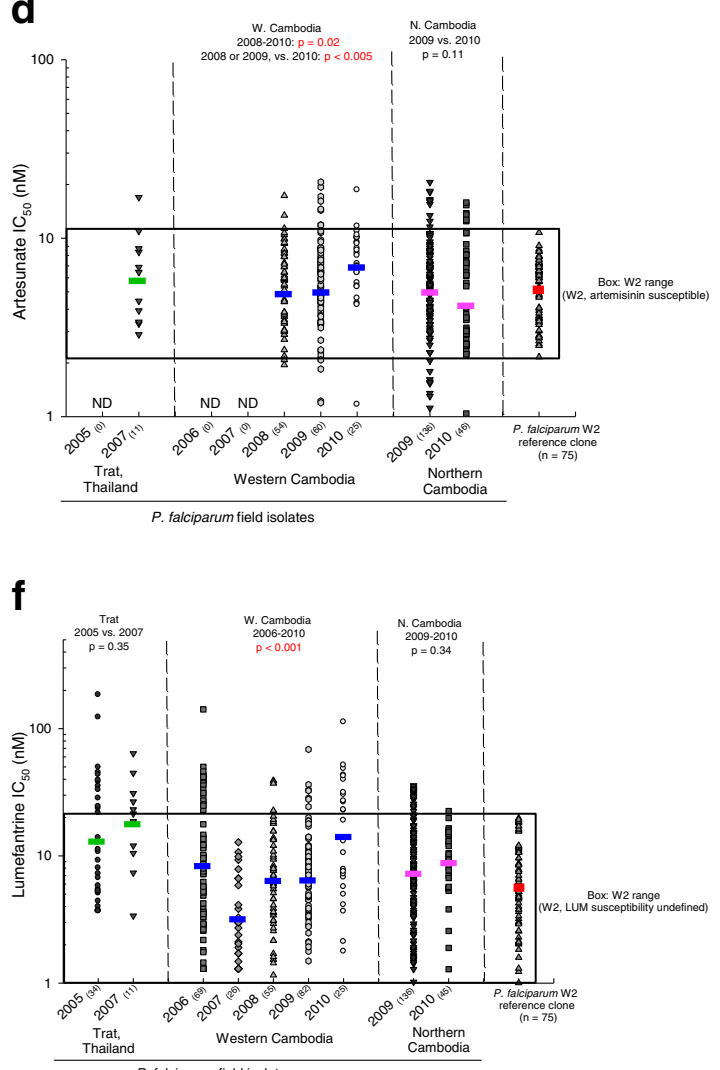

$P$. falciparum field isolates

Figure 2 (See legend on next page.) 
(See figure on previous page.)

Figure 2 (a-g): In vitro HRP-2, P. falciparum field isolate $\mathrm{IC}_{50}$ values (nM), determined by HRP-2 against 7 drugs shown as a scatter plots, with geometric mean (GM; solid color bars), by year and region. Sample numbers, in parentheses, are next to each year. $P$ values at top of graphs determined by Mann-Whitney ( 2 groups) or Kruskal-Wallis. ( $>2$ groups) tests; $p<0.05$ in red. P. falciparum W2 reference clone values for each drug shown at far right (GM, solid red bars); boxes denote ranges. Dashed horizontal lines (green) on CQ, MQ and QN graphs represent approximate historical. $I C_{50}$ values, denoting clinical "resistance". $\mathrm{nM}=$ nanomolar. $\mathrm{ND}=$ not done.

resistance, first described in subjects in western Cambodia in $2005[7,17,18]$. Statistically significant increases in GM IC 50 values for DHA in Trat Province, Thailand, adjacent to the Cambodian border, from 2005 to 2007, coincided with declining efficacy of AS + MQ in Thailand [19]. These observations may reflect $a>30$ year history of artemisinin use in this region.

In western Cambodia, a steady increase in $\mathrm{GM} \mathrm{IC}_{50}$ values for CQ from 2006 to 2010 was observed. This may reflect continued drug pressure due to its use for $P$. vivax blood stage treatment, as well as widespread unregulated availability. This is in contrast to the situation in parts of Africa, where the introduction of ACTs and withdrawal of CQ use has led to a reduction in mean $\mathrm{IC}_{50}$ values from those recorded when CQ was the firstline treatment for P. falciparum infections [20,21].

$\mathrm{QN}$ showed no remarkable trends in $\mathrm{GM} \mathrm{IC}_{50}$ values, paralleling continued effectiveness of this 2 nd line agent. For LUM, not widely used in Cambodia, increasing GM $\mathrm{IC}_{50}$ values in western Cambodia from 2006-2010, in parallel with trends in other drugs, possibly mirrored increases in MQ $\mathrm{IC}_{50} \mathrm{~s}$ (discussed below). For PPQ, the clinical relevance of our preliminary in vitro $\mathrm{IC}_{50}$ data remains unclear. Of note, $15 \%$ of subjects in two recent malaria treatment trials in Cambodia had detectable pretreatment PPQ levels, suggesting increasing drug pressure [22]. Continued in vivo and ex vivo monitoring of $\mathrm{PPQ}$, the recently adopted first-line partner drug for DHA in Cambodia, is of paramount importance.

In western Cambodia, MQ GM IC 50 values showed a steady increase from 2006 to 2010, and comparably high $\mathrm{GM} \mathrm{IC}_{50}$ values were observed in northern Cambodia in 2009-2010; all were well above the proposed WHO historical cut-off indicative of clinical MQ monotherapy "resistance", paralleling reduced clinical efficacy of MQ in this region $[23,24]$. The cause of reduced MQ sensitivity (and possibly LUM) is generally accepted to be related to increased Pfmdr1 copy number, so the association of increased MQ GM $\mathrm{IC}_{50} \mathrm{~S}$ with a recent description of reduced Pfmdr1 copy numbers in western Cambodia from 2005 to 2007 is unclear [25]. The WHO 2010 Global Report suggests this molecular event was due to a switch in treatment policy from MQ-AS to DHA-PPQ [4]; if so, a continued rise in MQ mean $\mathrm{IC}_{50}$ values to 2010 is potentially concerning. As before, unregulated availability of antimalarial medications during that period may have been a contributing factor. Notably, MQ-AS still appears to retain high efficacy despite reduced in vitro sensitivity to both drugs, shown most recently in a trial comparing mefloquine-artesunate with pyronaridine-artesunate [26].

For northern Cambodia, little is known about $\mathrm{IC}_{50}$ malaria drug susceptibility [27]. Relatively high $\mathrm{GM} \mathrm{IC}_{50}$ values in northern Cambodia in 2009 and 2010 are supported by antecedent $\mathrm{GM} \mathrm{IC}_{50}$ values in eastern Thailand and western Cambodia [27-29]. In Thailand, GM $\mathrm{IC}_{50}$ values for $\mathrm{CQ}, \mathrm{MQ}, \mathrm{QN}$ and $\mathrm{LUM}$ increased from 2005 to 2007, an increase mirrored in nearby western Cambodia, starting in 2006. QN GM $\mathrm{IC}_{50}$ values remained below the WHO historic cut-off of $315 \mathrm{nM}$ denoting "resistance", whereas $\mathrm{CQ}$ and $\mathrm{MQ}$ GM $\mathrm{IC}_{50}$ values rose above WHO historic cut-off values, and DHA showed marked increases in both countries. These trends followed drug policies during the survey period, with AS-MQ the first-line regimen for P. falciparum, and $C Q$ as the first-line agent for blood stage P. vivax in both Thailand and Cambodia.

In western Cambodia, measured annually 2006-2010, statistically significant, relatively steady increases in GM $\mathrm{IC}_{50}$ values for $\mathrm{CQ}, \mathrm{MQ}, \mathrm{QN}, \mathrm{AS}, \mathrm{DHA}$ and LUM were noted. However, GM IC 50 values dropped in 2007 , versus 2006, but then steadily increased from 2008 to 2010 . It is unclear why $\mathrm{GM} \mathrm{IC}_{50}$ decreases occurred in 2007 only. Review of data from 2007 showed a smaller sample size $(n=26)$ compared to other years, although the location of sampled sites was unchanged. Interestingly Lim et al. observed a similar dip in $\mathrm{IC}_{50}$ values for a range of antimalarial drugs in 2006, and attributed the observation to sampling bias since most samples that year were collected from a single, new field site; the data was included in the report for completeness and so that future comparisons could be made [27]. This perhaps illustrates the importance considering factors such as sampling bias when interpreting antimalarial drug $\mathrm{IC}_{50}$ surveys.

HRP-2 assays with IEV isolate processing conducted at field laboratories, which are simpler techniques than radioisotopic assays and culture-adaptation, may also reduce clonal selection and better preserve sub-populations of susceptible and potentially drug resistant parasites [11]. In this survey about $75 \%$ of HRP-2 IEV assays were successful, and $\mathrm{W} 2$ clone $\mathrm{IC}_{50}$ values for 
$\mathrm{CQ}, \mathrm{MQ}, \mathrm{QN}$ and $\mathrm{AS}$ were within expected ranges, providing context for falciparum isolate $\mathrm{IC}_{50}$ values. This bodes well for field based HRP-2 IEV assays. Moreover, GM IC 50 values reported here generally paralleled other published data from eastern Thailand and Cambodia, which assayed $P$. falciparum isolates by ${ }^{3} \mathrm{H}$-hypoxanthine uptake $[28,30]$. For example, a comparison of western Cambodia GM IC 50 ranges from 2001 to 2007 [27], with these results were, respectively (nM): CQ (131-237 vs. $96-242)$, MQ (12-57 vs. 7-58), QN (94-302 vs. 53163), and AS (0.6-1.8 vs.5.1-6.8). The higher AS GM $\mathrm{IC}_{50}$ range reported here could reflect continuing emergence of artemisinin resistance, paralleling $\mathrm{GM} \mathrm{IC}_{50}$ increases for AS and DHA from 2008 to 2010. Alternatively, it might reflect methodological differences, which affect drug or parasite behaviour, illustrating the importance of inter-assay consistency.

Trends in $\mathrm{IC}_{50}$ values, coupled with molecular marker assays, help track emergence and spread of anti-malarial drug resistance. For the artemisinins, although associations between validated resistance markers, treatment outcome and $\mathrm{IC}_{50}$ susceptibility remain elusive $[18,31]$., in part because the clinical definition of artemisinin "resistance" is unclear; the converse is not true for partner drugs, such as $\mathrm{MQ}$ and $\mathrm{CQ}$, which have established thresholds of resistance and validated molecular markers. Nonetheless, determining AS and DHA GM IC 50 values in a substantial number of $P$. falciparum isolates from 2005 to 2010 establishes a baseline which may be useful for future comparisons if evidence of reduced artemisinin susceptibility grows, and especially if the methodology remains consistent.

\section{Conclusion}

Increases in $\mathrm{GM} \mathrm{IC}_{50}$ values for a range of important anti-malarial drugs in a region of emerging drug resistance underscores the importance of harmonizing methodologies that allow for accurate comparison between geographical locations, and over time, so that potentially important trends in drug susceptibility can be identified.

\section{Competing interests}

The authors declare that they have no competing interests.

\footnotetext{
Acknowledgments

We thank AFRIMS and Cambodian clinical and laboratory field teams for their support. This work was supported by numerous organizations. Training of medical staff, capacity building and facility upgrades were provided by Global Emerging Infections Surveillance (GEIS) Program, US Department of Defense. Additional funding for some of the work was received from US Department of Defense Global Emerging Infections System, Silver Spring, Maryland, USA, Bill \& Melinda Gates Foundation World Health Organization (via World Health Organization), Medicines for Malaria Venture (MMV), and US Army Military Infectious Disease Research Program (MIDRP) and US Army Medical Materiel Development Activity (USAMMDA), Fort Detrick, Maryland, USA. We thank Ms. Tippa Wongstitwilairoong for making the map.
}

The opinions and assertions contained herein are the private views of the authors and are not to be construed as official or as reflecting the views of the U.S. Department of the Army.

Presented in part at 2010 Annual Meeting of the American Society of Tropical Medicine and Hygiene, Atlanta, GA USA.

\section{Author details}

'Department of Immunology and Medicine, US Army Medical Corps, Armed Forces Research Institute of Medical Sciences (USAMC-AFRIMS), Bangkok, Thailand. ${ }^{2}$ The National Center for Parasitology, Entomology and Malaria Control (CNM), Phnom Penh, Cambodia. Institute of Specific Prophylaxis and Tropical Medicine, Medical University of Vienna, Kinderspitalgasse 15, Vienna, A-1090, Austria. ${ }^{4}$ Bureau of Vector-Borne and Zoonotic Diseases, Thailand Ministry of Public Health, Nonthaburi, Thailand.

\section{Authors' contributions}

Study designs, oversight, data interpretation, manuscript preparation: CL, ST, DS (Dr Socheat), YS, HN, DB, KS, WR, WS, MF, SC (Dr. Suwanna), AT, DS (Dr Saunders), DW Subject recruitment, interactions: DS (Dr Sea), YS, SC (Ms. Chann), NB, SS (Ms Sabaithip) Conducted experiments, summarized data: ST, KS, WR, SC, KY, SS (Ms Siratchana), PC. All authors read and approved the final manuscript.

Received: 2 April 2012 Accepted: 13 June 2012

Published: 13 June 2012

\section{References}

1. Desjardins RE, Canfield CJ, Haynes JD, Chulay JD: Quantitative assessment of antimalarial activity in vitro by a semiautomated microdilution technique. Antimicrob Agents Chemother 1979, 16:710-718.

2. Webster HK, Boudreau EF, Pavanand K, Yongvanitchit K, Pang LW Antimalarial drug susceptibility testing of Plasmodium falciparum in Thailand using a microdilution radioisotope method. Am J Trop Med Hyg 1985, 34:228-235.

3. Wongsrichanalai C, Pickard AL, Wernsdorfer WH, Meshnick SR: Epidemiology of drug-resistant malaria. Lancet Infect Dis 2002, 2:209-218.

4. World Health Organization: Global report on antimalarial efficacy and drug resistance: 2000-2010. Geneva: WHO; 2010.

5. Noedl $H$, Attlmayr B, Wernsdorfer WH, Kollaritsch H, Miller RS: A histidinerich protein 2-based malaria drug sensitivity assay for field use. Am J Trop Med Hyg 2004, 71:711-714.

6. Noedl H, Bronnert J, Yingyuen K, Attlmayr B, Kollaritsch H, Fukuda M: Simple histidine-rich protein 2 double-site sandwich enzyme-linked immunosorbent assay for use in malaria drug sensitivity testing. Antimicrob Agents Chemother 2005, 49:3575-3577.

7. Noedl H, Se Y, Schaecher K, Smith BL, Socheat D, Fukuda MM: Evidence of artemisinin-resistant malaria in western Cambodia. NEJM 2008, 359:26192620.

8. Cui W: WHO urges the phasing out of artemisinin based monotherapy for malaria to reduce resistance. BMJ 2011, 342:d2793.

9. Incardona S, Vong S, Chiv L, Lim P, Nhem S, Sem R, Khim N, Doung S, Mercereau-Puijalon O, Fandeur T: Large-scale malaria survey in Cambodia: novel insights on species distribution and risk factors. Malar J 2007, 6:37.

10. Noedl H, Teja-Isavadharm P, Miller RS: Nonisotopic, semiautomated plasmodium falciparum bioassay for measurement of antimalarial drug levels in serum or plasma. Antimicrob Agents Chemother 2004, 48:44854487.

11. Akala HM, Eyase FL, Cheruiyot AR, Omondi AA, Ogutu BR, Waters NC, Johnson JD, Polhemus ME, Schnabel DC, Walsh DS: Anti-malarial drug sensitivity profile of western Kenya Plasmodium falciparum field isolates determined by a SYBR Green I in vitro assay, and molecular analysis. Amer J Trop Med Hyg 2011, 85:34-41.

12. Mbaisi A, Liyala P, Eyase F, Achilla R, Akala H, Wangui J, Mwangi J, Osuna F, Alam U, Smoak BL, Davis JM, Kyle DE, Coldren RL, Mason C, Waters NC: Drug susceptibility and genetic evaluation of Plasmodium falciparum isolates obtained in four distinct geographical regions of Kenya. Antimicrob Agents Chemother 2004, 48:3598-3601.

13. World Health Organization: Mark III in vitro micro-test for the assessment of the response of Plasmodium falciparum to chloroquine, mefloquine, quinine, amodiaquine, sulfadoxine/pyrimethamine, and artemisinin.: ; CTD/MAL/9720 Rev 22001. 
14. Teja-Isavadharm P, Siriyanonda D, Siripokasupkul R, Apinan R, Chanarat N, Lim A, Wannaying S, Saunders D, Fukuda MM, Miller RS, Weina PJ, Melendez $\mathrm{V}$ : A simplified liquid chromatography-mass spectrometry assay for artesunate and dihydroartemisinin, its metabolite, in human plasma. Molecules 2010, 15:8747-8768.

15. Bethell $D$, Se $Y$, Lon C, Socheat $D$, Saunders D, Teja-Isavadharm $P$, Khemawoot P, Darapiseth S, Lin J, Sriwichai S, Kuntawungin W, Surasri S, Lee SJ, Sarim S, Tyner S, Smith B, Fukuda MM: Dose-dependent risk of neutropenia after 7-day courses of artesunate monotherapy in Cambodian patients with acute Plasmodium falciparum malaria. Clin Infect Dis 2010, 51:e105-114.

16. ICEstimator (version 1.2)., . Available from: http://www.antimalarialicestimator.net/Methodlntro.htm.

17. Dondorp AM, Yeung S, White L, Nguon C, Day NP, Socheat D, von Seidlein $L$ : Artemisinin resistance: current status and scenarios for containment. Nat Rev Microbiol 2010, 8:272-280.

18. Bethell D, Se Y, Lon C, Tyner S, Saunders D, Sriwichai S, Darapiseth S, TejaIsavadharm P, Khemawoot P, Schaecher K, Ruttvisutinunt W, Lin J, Kuntawungin W, Gosi P, Timmermans A, Smith B, Socheat D, Fukuda MM: Artesunate dose escalation for the treatment of uncomplicated malaria in a region of reported artemisinin resistance: a randomized clinical trial. PLoS One 2011, 6:e19283.

19. Vijaykadga S, Rojanawatsirivej C, Cholpol S, Phoungmanee D, Nakavej A, Wongsrichanalai C: In vivo sensitivity monitoring of mefloquine monotherapy and artesunate-mefloquine combinations for the treatment of uncomplicated falciparum malaria in Thailand in 2003. Trop Med Int Health 2006, 11:211-219.

20. Fall B, Diawara S, Sow K, Baret E, Diatta B, Fall KB, Mbaye PS, Fall F, Dieme Y, Rogier C, Wade B, Bercion R, Pradines B: Ex vivo susceptibility of Plasmodium falciparum isolates from Dakar, Senegal, to seven standard anti-malarial drugs. Malar J 2011, 10:310.

21. Ndiaye D, Patel V, Demas A, LeRoux M, Ndir O, Mboup S, Clardy J, Lakshmanan V, Daily JP, Wirth DF: A non-radioactive DAPI-based highthroughput in vitro assay to assess Plasmodium falciparum responsiveness to antimalarials-increased sensitivity of $P$. falciparum to chloroquine in Senegal. Am J Trop Med Hyg 2010, 82:228-230.

22. Hodel EM, Genton B, Zanolari B, Mercier T, Duong S, Beck HP, Olliaro P, Decosterd LA, Ariey F: Residual antimalarial concentrations before treatment in patients with malaria from Cambodia: indication of drug pressure. J Infect Dis 2010, 202:1088-1094.

23. Basco LK: Field application of in vitro assays sensitivity of human malaria parasites antimalarial drugs.: World Health Organization; 2007.

24. Wongsrichanalai C, Meshnick SR: Declining artesunate-mefloquine efficacy against falciparum malaria on the Cambodia-Thailand border. Emerg Infect Dis 2008, 14:716-719.

25. Imwong M, Dondorp AM, Nosten F, Yi P, Mungthin M, Hanchana S, Das D, Phyo AP, Lwin KM, Pukrittayakamee S, Lee SJ, Saisung S, Koecharoen K, Nquon C, Day NP, Socheat D, White NJ: Exploring the contribution of candidate genes to artemisinin resistance in Plasmodium falciparum. Antimicrob Agents Chemother 2010, 54:2886-2892.

26. Rueangweerayut $R$, Phyo AP, Uthaisin $C$, Poravuth $Y$, Binh $T Q$, Tinto $H$, Penali LK, Valecha N, Tien NT, Abdulla S, Borghini-Fuhrer I, Duparc S, Shin CS, Fleckenstein L: Pyronaridine-artesunate versus mefloquine plus artesunate for malaria. N Engl J Med 2012, 366:1298-1309.

27. Lim P, Wongsrichanalai C, Chim P, Khim N, Kim S, Chy S, Sem R, Nhem S, Yi P, Duong S, Bouth DM, Genton B, Beck HP, Gobert JG, Rogers WO, Coppee $J Y$, Fandeur T, Mercereau-Puijalon O, Ringwald P, Le Bras J, Ariey F: Decreased in vitro susceptibility of Plasmodium falciparum isolates to artesunate, mefloquine, chloroquine, and quinine in Cambodia from 2001 to 2007. Antimicrob Agents Chemother 2010, 54:2135-2142.

28. Chaijaroenkul W, Bangchang KN, Mungthin M, Ward SA: In vitro antimalarial drug susceptibility in Thai border areas from 1998-2003. Malar J 2005, 4:37.

29. Suwandittakul N, Chaijaroenkul W, Harnyuttanakorn P, Mungthin M, Na Bangchang K: Drug resistance and in vitro susceptibility of Plasmodium falciparum in Thailand during 1988-2003. Korean J Parasitol 2009, 47:139144.

30. Chaijaroenkul W, Wisedpanichkij R, Na-Bangchang K: Monitoring of in vitro susceptibilities and molecular markers of resistance of Plasmodium falciparum isolates from Thai-Myanmar border to chloroquine, quinine, mefloquine and artesunate. Acta Trop 2010, 113:190-194.
31. Dondorp AM, Nosten F, Yi P, Das D, Phyo AP, Tarning J, Lwin KM, Ariey F, Hanpithakpong W, Lee SJ, Ringwald P, Silamut K, Imwong M, Chotivanich K, Lim P, Herdman T, An SS, Yeung S, Singhasivanon P, Day NP, Lindegardh N, Socheat $D$, White NJ: Artemisinin resistance in Plasmodium falciparum malaria. N Engl J Med 2009, 361:455-467.

doi:10.1186/1475-2875-11-198

Cite this article as: Tyner et al:: Ex vivo drug sensitivity profiles of Plasmodium falciparum field isolates from Cambodia and Thailand, 2005 to 2010 , determined by a histidine-rich protein-2 assay. Malaria Journal 2012 11:198.

\section{Submit your next manuscript to BioMed Central and take full advantage of:}

- Convenient online submission

- Thorough peer review

- No space constraints or color figure charges

- Immediate publication on acceptance

- Inclusion in PubMed, CAS, Scopus and Google Scholar

- Research which is freely available for redistribution

Submit your manuscript at www.biomedcentral.com/submit
C) Biomed Central 